\title{
Cybersex in Portuguese Chatrooms: A Study of Sexual Behaviors Related to Online Sex
}

\author{
ALEXANDRA CARVALHEIRA \\ Clinical Psychologist, Sexology Clinic of Coimbra's University Hospital, Portugal \\ FRANCISCO ALLEN GOMES \\ Psychiatrist, Private practice, Coimbra, Portugal
}

The present article is about a particular form of sexual activity on the Internet: cybersex in chatrooms - in Portuguese by Portuguese people. This study aims to identify the reasons for engaging in cybersex on chats and the behavioral domains that characterize this activity. To carry out the study, we developed a self-report questionnaire that we made available on a website. The sample was collected online $(\mathrm{n}=400)$ through the Portuguese Internet Relay Chat. Factor analyses revealed seven domain structures: (a) social skills, (b) preference for cybersex, (c) filter for a later date, (d) sex by phone, (e) fantasies, ( $f$ ) "using masks," and (g) impact on real relationships. We found a huge variety of sexual attitudes and behaviors connected to cybersex in chatrooms and the existence of two major trends: (a) people that use these chats as a starting place for offline relationships (online anonymity prevents the fear of rejection and social sanctions in real life), and (b) people who want and prefer online sex without any interest in further real contacts.

\footnotetext{
We wish to thank all those who answered the questionnaire and made this study possible, as well as the channel operators on the IRC. Special thanks to Dr. Ana A. Gomes for her help with the statistical analysis, to Prof. Helena Azevedo for her critical review of our work, and to Prof. Manuel João Quartilho for his helpful words and comments. We also thank "sexualidades.com," particularly Dr. Joaquim Lopes, for technical support. This work was supported by a grant from the Fundação para a Ciência e Tecnologia.

Address correspondence to Alexandra Carvalheira, Consulta de Sexologia, Hospital da Universidade de Coimbra, 3000 Coimbra, Portugal. E-mail: anacarvalheira@mail.telepac.pt
} 
"If you want sex ... it is only a keyboard away" (Wysocki, 1998)

The Internet has been a powerful means of communication, with deep consequences as far as interpersonal relationships are concerned. The Internet is a world without boundaries, a free world that because of its special features-accessibility, ease of use, and low cost-allows relational possibilities, romantic relationships, and access to all kinds of sexual pursuits: "The influence of the Internet on sexuality is likely to be so significant that it will ultimately be recognized as the cause of the next "sexual revolution"” (Cooper, Boies, Maheu, \& Greenfield, 2000, p. 519).

There are many different reasons for looking for sex on the Internet. One of the most widely known is the use of sites with pornographic content. According to Childs (1994), more than 50\% of all online communication is about sex. Cooper, Morahan-Martin, Mathy, and Maheu (2002) assert that Internet sexual activity can take on a variety of forms, including recreation, entertainment, education, purchasing of sexual materials, the search for sexual partners, sexual arousal, sharing of erotica, as well as cybersex as a subcategory of online sexual activity. According to Cooper, Putnam et al. (1999, p. 81), "Internet sexuality ... is best viewed as falling along a continuum rating from normal and life-enhancing forms of sexual expression and explorations, to problematic and pathological expressions." And along this continuum of behaviors, anonymity is the major mediator. Anonymity regarding self-disclosure and intimacy is a key factor to consider when studying differences or similarities between face-toface and online relationships. Anonymity can provide security and be a protector and a liberator, because it makes it easier for the individual to express his or her interests and desires. The Internet "can facilitate intimacy in users" (Cooper \& Sportolari, 1997, p. 7). Anonymity can help unsociable or stigmatized people because there are no social sanctions, embarrassment, or fear of negative reactions: "The anonymity of Internet interactions allowed these individuals to find similar others who shared the stigmatized aspect, where finding similar others in non-anonymous real-life settings is virtually impossible" (McKenna, Green, \& Smith, 2001, p. 303). On the one hand, we can recognize positive implications and consequences of anonymity in online relationships.

On the other hand, we can find in cyberspace individuals that use anonymity to present themselves differently from the offline world and do things that they are not able to do with their real partner, distorting important aspects of themselves. Thus, anonymity can play an important role in protecting the individual from real difficulties, because it does not allow the confrontation necessary to developing intimacy capacity. According to Schnarch (1997, p. 17), "Cyberdating is the epitome of selfpresentation rather than self-confrontation and self-disclosure in the presence of a partner (i.e., intimacy)." The question is: What is the major role 
of anonymity? Does it play a liberating role by making self-disclosure and intimacy easier, or does it perpetuate difficulties in intimacy and in establishing a relationship?

When it comes to the impact of online sexual activities on people's lives, some studies show that there are no negative consequences for the majority of individuals. Cooper et al. (2002) conducted a study through the MSNBC website that explored the general profile of people who engage in online sexual activity and found that the majority of individuals who use the Internet for sexual pursuits reported that their use was not causing problems in their lives (Cooper et al., 2002). Nevertheless, other studies have shown that for a small but significant minority, online sexual activity generates serious problems in their lives, including relational problems and Internet abuse (Greenfield, 1999; Morahan-Martin \& Schumacher, 2000).

Cybersex in chats refers to starting a relationship with someone in order to perform sexual activity with one or more partners through real-time written communication of erotic-sexual content. The objective is sexual arousal, and some participants use a web camera, which allows viewing of partners, also in real time. These sexual behaviors take place in the so-called chats, that is, channels created in cyberspace. The raw material of this erotic communication is writing, so it is restricted to mere lines of text on the screen. There are no body signs and, therefore, the whole range of nonverbal communication is absent. This leads to the emergence of a new language: emoticons (emotion + icons). The emotional icon is a pictorial expression of the emotion or feeling of the moment created by keyboard symbols. Thus, there may be exchanges of kisses, true or ironic smiles, and expressions of sadness, cheerfulness, hugs or laughs, among many others (Carvalheira \& Gomes, 2002a).

The great novelty is the absence of the body. However, in online sex, the sensory element is present-clearly perceived by the bodies-as is the imaginary component. Therefore, these two fundamental components of any erotic date are present. The novelty lies in the fact that the bodies are not in direct contact, so physical interaction is absent. The phenomenon that we try to understand and identify in this article is a sexuality pattern where the absence of physical interaction is preferred. In the literature, we can find two works by the same author that illustrate this theme very well. Vox (Baker, 1992) is a novel about an erotic telephone conversation or, in other words, a sexual relationship mediated by the phone. The Fermata (Baker, 1994) is a sequence of short stories, where the characters never achieve any kind of physical contact. Nevertheless, the book is full of imagery and sensuality, revealing a very elaborated type of sexuality. Both works have in common sex without physical interaction between main characters. In his anthropological studies of sexuality, Félix López (1997) asserts that direct contact is a basic human necessity, a fundamental element of intimacy. Human beings are essen- 
tially orientated toward intimate interaction with other individuals and are perfectly equipped for skin contact.

The present study aims at identifying the reasons for engaging in cybersex on chats and the behavioral domains that characterize this activity. It also attempts to provide demographic data about users and time spent online for cybersex, to analyze the role played by anonymity, and to verify the existence of individuals that prefer this type of sexual relationship to the detriment of other kinds of sexual activity.

\section{METHODS}

\section{The Instrument}

Because there was no instrument available to collect the data, we had to create one. We considered the following in building a self-report questionnaire: (a) clinical cases of Internet-addictive behavior, especially addiction to pornographic material and chatrooms; (b) literature on this phenomenon (Cooper, Scherer, et al., 1999; Wysocki, 1998); (c) nonstructured interviews conducted by us of participants in chat-lines of predominantly sexual content. As a result, a series of interesting domains for study came up: (a) the role of anonymity, one of the main characteristics of online relationships, and use of false identities, "masks" or, conversely, the expression of one's feelings and desires, that is, "removing masks"; (b) individuals' social skills, an aspect related to the previous one in that interpersonal difficulties can be overcome in online situations; (c) cybersex used as an exclusive preference (we would ascertain the existence of a group of subjects who prefer this type of sexual activity); (d) the use of chats as starting point for real relationships outside chat-lines; (e) the role of fantasies in cybersex, which emphasizes the imaginary world; (f) the impact of cybersex on real relationships (i.e., we would assess whether online sex complements or replaces a real relationship); (g) addictive behavior, when cybersex is one of the most important activities in the lives of users who spend too much time engaging in this type of activity and, as a result, have no time for other things.

After considering the seven domains, we generated 58 items (see Appendix), which we presented to a sexology researcher and a clinician who rated the face validity and clarity of the items. We tested the initial face validity of questionnaire items, identified by experts, then we conducted a study aimed at further refining the questionnaire. This study was carried out online, through interviews with users, to whom we presented the 58 items and asked to comment on the clarity of the items, the relevance of the content, and whether any items should be added, deleted, or modified. The purpose of this initial step was to meet basic psychometric criteria, that is, to be clear and understandable and to provide comprehensive response choices. Therefore, in response to face validity and initial study interviews, we al- 
tered some items and excluded 10-items 2, 10, 12, 23, 25, 30, 32, 33, 46, and 50 (Carvalheira \& Gomes, 2002a).

We assessed Internal consistency using the Cronbach alpha statistic formula. The results of Pearson's correlation analysis between each item and the total (including and excluding the item) and the alpha coefficients excluding the items one by one led us to exclude 5 items (1, 6, 9, 24, and 31) that harmed the questionnaire homogeneity and diminished internal consistency. The questionnaire had 43 items and a Cronbach alpha of .94, which reveals a good internal consistency and uniformity and coherence between the answers given and the items.

We performed a factor analysis to assess the underlying domain structure of the questionnaire and to evaluate factorial validity, that is, the degree to which each item is related to the hypothesized domain with which it is associated. We evaluated internal consistency of the items within each factor using the Cronbach alpha formula.

Demographic data included sex, job, and age. There was another variable to consider: time spent online for cybersex ( $2 \mathrm{hr}$ per week; $5 \mathrm{hr}$ per week; 1-2 hr per day; over $2 \mathrm{hr}$ per day). By choosing this type of answer, as well as by constituting age class intervals, we wanted to facilitate people's answers to the questionnaire and eliminate possible inhibitions.

The questionnaire was composed of 43 items designed to gather information on the seven domains, with answers on a Likert scale: totally disagree; partially disagree, neither agree or disagree, partially agree, totally agree.

\section{Procedure}

We posted the questionnaire developed from this process online. After undergoing graphic design work, the questionnaire was uploaded on an Internet website (www.sexualidades.com/sexoonline; the 58 items were presented in a random order). Our field of work was the Portuguese Internet Relay Chat (IRC). We entered some chatrooms of predominantly sexual content at different times of day and night to disseminate the questionnaire, to encourage users to participate in the study by answering the questionnaire, and to carry out interviews with users. We also contacted some chat-line operators, who collaborated by disseminating the questionnaire. We gathered data between May 2001 and January 2002. For the statistical study, we used SPSS, version 10.0 for Windows.

\section{Sample}

During the period of study, we received 468 questionnaires, of which we excluded 68 that had not been filled out properly $(N=400)$. Of the total, 313 (78.3\%) were filled out by men, $46(11.5 \%)$ were filled out by women, and 41 (10.3\%) not answered. 
TABLE 1. Distribution by Age

\begin{tabular}{cc}
\hline Age & $\%$ \\
\hline Under 15 & 3.5 \\
$15-19$ & 30.8 \\
$20-24$ & 28.5 \\
$25-29$ & 15.8 \\
$30-34$ & 4.5 \\
$35-39$ & 1.8 \\
$40-44$ & 3.3 \\
$45-49$ & 0.8 \\
$50-55$ & 0.3 \\
over 55 & 1.0 \\
\hline
\end{tabular}

Distribution by age is presented in Table 1 . Considering the professional group, $47 \%$ are students, $22.6 \%$ did not answer, and the rest belong to a range of professional groups, with a high degree of diversity. The sample is self-selected.

\section{RESULTS}

\section{Descriptive Results}

Table 2 shows that a minority of individuals spend more than $2 \mathrm{hr}$ a day online (8.3\%). Results reveal a variety of behaviors and reasons for engaging in cybersex. On the one hand, these chat-lines provide an opportunity to meet partners for future real meetings and a quick way to select people with the same sexual interests for a subsequent date outside chatrooms. On the other hand, these results also reveal a group of subjects who, although a minority, show a preference for sex on chat-lines, as shown in Table 3.

Anonymity is the main element of everything that goes on in chatrooms and seems to have a protective role, in the sense that it allows individuals with limited social skills to overcome the difficulties of face-to-face relationships. Anonymity also seems to facilitate social deinhibition and allows individuals to "take off their masks," giving them the possibility to honestly express their interests and desires (see Table 3).

An idea that seems to be shared by the great majority of individuals is the possibility of exploiting and sharing sexual fantasies in chatrooms. Fan-

TABLE 2. Time Spent Online for Cybersex

\begin{tabular}{cr}
\hline Time spent online & $\%$ \\
\hline 2 hr per week & 48.8 \\
1-2 hr per day & 11.8 \\
more than 2 hr per day & 8.3 \\
no answer & 17.5 \\
\hline
\end{tabular}


TABLE 3. Items Sample and Answers Expressed in Percentage

\begin{tabular}{|c|c|c|c|}
\hline Item & $\begin{array}{l}\text { Totally } \\
\text { disagree }\end{array}$ & $\begin{array}{l}\text { Partially } \\
\text { agree }\end{array}$ & $\begin{array}{l}\text { Totally } \\
\text { agree }\end{array}$ \\
\hline \multicolumn{4}{|l|}{ Cybersex in chats } \\
\hline $\begin{array}{l}\text { I use these chatrooms exclusively to set up } \\
\text { dates with sexual aims. }\end{array}$ & 50.3 & 10.5 & 8.5 \\
\hline $\begin{array}{l}\text { It is easier to meet people with the same } \\
\text { views and sexual preferences online. }\end{array}$ & 7.3 & 39 & 4 \\
\hline $\begin{array}{l}\text { I feel more pleasure with an online } \\
\text { relationship than with a real one. }\end{array}$ & 75.3 & 2 & 2.3 \\
\hline $\begin{array}{l}\text { Online sexual activity is more } \\
\text { satisfactory than a real relationship. }\end{array}$ & 70.5 & 3 & 3.8 \\
\hline $\begin{array}{l}\text { Cybersex is one of the most } \\
\text { important activities in my life } \\
\text { at the moment. }\end{array}$ & 67.5 & 7 & 4.5 \\
\hline \multicolumn{4}{|l|}{ Anonymity and social skills } \\
\hline $\begin{array}{l}\text { I can honestly say to the other person } \\
\text { what I feel and think online. }\end{array}$ & 4.8 & 32.3 & 38.8 \\
\hline $\begin{array}{l}\text { I can be more open and straightforward } \\
\text { than in a face-to-face relationship. }\end{array}$ & 13.5 & 31.3 & 23 \\
\hline $\begin{array}{l}\text { In a real relationship I get nervous } \\
\text { during the first dates. }\end{array}$ & 11.5 & 33.8 & 19.5 \\
\hline If I'm rejected online & & & \\
\hline I don't suffer that much. & 6.8 & 27 & 39.8 \\
\hline \multicolumn{4}{|l|}{ Sexual fantasies } \\
\hline $\begin{array}{l}\text { Fantasy is what rules } \\
\text { an online relationship. } \\
\text { It is very exciting to }\end{array}$ & 2 & 33 & 55.5 \\
\hline share fantasies online. & 4.8 & 35 & 35 \\
\hline \multicolumn{4}{|l|}{ Impact on real relationships } \\
\hline $\begin{array}{l}\text { Cybersex can be a good complement } \\
\text { to the real relationship. }\end{array}$ & 14 & 28.8 & 14 \\
\hline $\begin{array}{l}\text { It can intensify and improve } \\
\text { my real relationship with my partner. }\end{array}$ & 17.3 & 28.3 & 14 \\
\hline Addictive behaviors & & & \\
\hline $\begin{array}{l}\text { Cybersex occupies most of my day. } \\
\text { After discovering } \\
\text { cybersex I have no longer }\end{array}$ & 74 & 2.8 & 2.5 \\
\hline time to do other things. & 73 & 4.5 & 4.3 \\
\hline
\end{tabular}

tasies play a major role in this online activity. Individuals also keep sexual relations in chatrooms while having a real relationship outside the virtual world at the same time (see Table 3 ). The results also point to the existence of a small minority with addictive behavior; cybersex is their main interest in life, and they have no time for other activities (see Table 3).

\section{Factor Analysis}

We conducted a principal components analysis using varimax rotation on the 43-item questionnaire answered by 400 subjects, which revealed 9 main factors with eigenvalues over 1.00. However, on the basis of the reading of 
the scree test (Catel) and high/moderate loading on one factor, we chose a 7 -factor solution that explained $58.086 \%$ of the total variance (Carvalheira \& Gomes, 2002b).

\section{FACTOR 1: SOCIAL SKILlS}

The first factor explained $14.12 \%$ of the variance and included 12 items related to social skills. This factor gathers items dealing with social embarrassment, fear of rejection, social anxiety and shyness, and the opportunity to express feelings, thoughts, and desires with greater security and less anxiety in an online situation. The fear of rejection is one of the main underlying issues in this factor. On this basis, we labeled this factor Social Skills (Figure 1).

\section{Factor 2: Preference for Cybersex}

Factor 2 explained $13.404 \%$ of the variance and included 9 items related to cybersex as the main preference. It aims at identifying individuals who prefer cybersex to any other form of sexual activity and includes items that assess the importance of cybersex in the life of the individuals, the degree of satisfaction in comparison with offline sex, and the level of individuals' involvement in this activity. On this basis, we labeled this factor Preference for Cybersex (Figure 2).

18. I am less ashamed of expressing some of my erotic and sexual desires.

37. In a real relationship I get nervous during the first dates.

36. In real situations I feel some anxiety on social occasions.

17. I am more daring in my sexual fantasies.

14. I feel more secure to express desires and fantasies that I wouldn't otherwise express. .65

15. I can be more open and straightforward than in a face-to-face relationship.

16. Online I can honestly say to the other person what I feel and think.

35. I have difficulties in establishing contacts with people of the opposite sex in real situations.

38. If I am rejected online I don't suffer that much.

29. Cybersex allows me to do things that are not possible in a real relationship.

39. I feel less anxious when I begin a relationship online. more easily.

FIGURE 1. 
Factor 2: Preference for cybersex

loading

52. After discovering cybersex I no longer had time to do other things.

51. Cybersex occupies most of my day.

.79

27. Online sexual activity is more satisfactory than real relationships.

28. Online sexual activity can be as satisfactory as real relationships.

26. I feel more pleasure in an online relationship than in a real one.

5. My online sexual activity is important for my personal fulfillment.

4. My online sexual activity is important in my life.

49. Cybersex is one of the most important activities in my life at the moment.

48. An online relationship allows me to get to sex quickly.

FIGURE 2.

\section{Factor 3: Filter for a Later Date}

Factor 3 translates the instrumental and provisional character of chatrooms for some individuals who want to use this channel exclusively as a starting point for a later real-life meeting. It groups items concerning the immediacy offered by chatlines in the search for and selection of people with the same interests and sexual preferences with the goal of establishing sexual contacts offline. This factor seeks to identify those individuals who, although not prferring cybersex, use chatrooms as a quick and easy way to set up real dates offline. On this basis, we labeled this factor Filter for a Later Date (Figure 3). This factor explains $8.331 \%$ of the variance.

Factor 3: Filter for a later date

loading

44. It is easier to meet people with the same views and sexual preferences online. 41. It's an effective way of meeting people in a later, real-life situation.

40. I use these chatrooms exclusively

to set up dates with sexual aims.

45. It is easier to find people with

the same sexual interests online.

42. It's a good way to make a

first selection of a partner for a real date. $\quad .55$

43. It's a good way to obtain

someone's cell phone number for a later date. $\quad .51$

53. I usually ask for a cell phone number. $\quad .51$

47. Online relationships allow for

a quicker conquest of the other person.

.68

.62

.61

.60

.37

FIGURE 3. 
Factor 4: Sex by phone

58. I prefer sex over the phone to cybersex.

55. I've already spoken on the phone about sex with people I met online.

56. Sex by phone arouses me.

57. Before setting up a date with someone in the real world, I like to speak with that person on the phone.

54. I like to hear the voice of somebody I met online. loading

.71

.66

.61

.55

.49

FIGURE 4 .

FaCtor 4: SeX By Phone

Factor 4 explains $6.273 \%$ of the variance and includes 5 items concerning individuals' preferences for sexual activity by phone. It includes items regarding the use of the telephone by users of chats, which can either be for sexual purposes or for mediating a future offline date. On this basis, we labeled this factor Sex by Phone (Figure 4).

FACTOR 5: FANTASIES

Factor 5 explained $5.970 \%$ of the variance and included 3 items that aimed at assessing the possibility of these chatline users exploring and sharing sexual and erotic fantasies. On this basis, we labeled this factor Fantasies (Figure 5).

\section{FACTOR 6: USING MasKS}

Factor 6 explains $5.027 \%$ of the variance and includes 3 items assessing the individual's ability to take on false identities, for example, by lying about themselves, playing roles or using "masks" in online relationships. The underlying issue in this factor is the role of anonymity, one of the main characteristics of online relationships. This factor contains items related to the hypothesis of playing roles and to the individuals' lack of honesty in their communications. On this basis, we labeled this factor Using Masks (Figure 6).

\section{Factor 5: Fantasies}

loading

3. It's a way of exchanging erotic

fantasies with someone and enriching my erotic experiences.

8. It is very exciting to share fantasies online.

7. It gives me the opportunity to

FIGURE 5. 
11. In online relationships I quite often use "masks" and take on different identities. 19. It's a matter of playing a role that has nothing to do with my real personality.

13. I can pretend whatever I want online and I've already done it some times.

.70

.62

FIGURE 6.

FACTOR 7: IMPACT ON REAL RELATIONSHIPS

Factor 7 explains $4.961 \%$ of the variance and includes 3 items that concern the positive consequences of cybersex for the lives of individuals, perhaps as a complement to a real relationship. On this basis, we labeled this factor Impact on Real Relationships (Figure 7).

Using the Cronbach alpha statistic, we determined internal consistency separately for the 7 domains and for the full scale score (Table 4).

\section{DISCUSSION}

The sample of 400 subjects shows a clear predominance of male participation in cybersex: $78.3 \%$ were men, $11.5 \%$ women, and $10.3 \%$ did not answer. These results lead to interesting questions: with whom do so many men have cybersex? And what is the meaning of women's absence from these chatrooms? The numbers show a large majority of male participants; however, our experience during the interviews raises some doubts about the low percentage of female participants. We interviewed some women who found it difficult to admit their presence in these chatrooms and their participation in this type of activity. We believe that a higher percentage of women use these chatrooms and that the $10.3 \%$ who do not answer this item could be women who do not wish to reveal their gender. Nevertheless, male participation undoubtedly predominates, for the pattern of sexuality we find in these chatrooms is unquestionably of the male type. It must also be noted

Factor 7: Impact on real relationships

loading

20. Cybersex can "spice up"

my real relationship.

.70

21. It can intensify and improve

my real relationship with my partner. $\quad .65$

22. Cybersex can be a good

complement to the real relationship.

.54

FIGURE 7. 
TABLE 4. Internal Consistency

\begin{tabular}{lc}
\hline Domain & Cronbach's alpha \\
\hline Social skills & .90 \\
Preference for cybersex & .90 \\
Filter for later date & .79 \\
Sex by phone & .74 \\
Fantasies & .68 \\
Using masks & .74 \\
Impact on real relationships & .75 \\
All items & .94 \\
\hline
\end{tabular}

that $59.3 \%$ of the respondents are between 15 and 24 years old, which reveals a mainly young population, $47 \%$ of whom are students.

Concerning the time spent with cybersex, it appears significant that $17.5 \%$ of participants did not answer and $8.3 \%$ spend more than $2 \mathrm{hr}$ a day on this activity. Related to these figures are the $4.3 \%$ of individuals who no longer had time for other things after discovering cybersex and also the 2.5\% for whom online sex occupies most of the day. These results point to the existence of a small but significant minority of individuals for whom sex in chatrooms is a central activity in their lives.

We conducted this study on the basis of the several behavior domains that characterize this population, which we later corroborated by factor analysis. From this analysis, social skills emerged as the key factor, being intimately connected with anonymity. Therefore, we verified the existence of a group of individuals with low social skills, having difficulties with interpersonal relationships, to whom anonymity provides not only protection by abolishing the barriers that come up in face-to-face relationships but also liberation by allowing the expression of desires and fantasies that could not otherwise be experienced. Anonymity allows many individuals to "take off their masks": "Online I can honestly say to the other person what I feel and think" (38.8\% totally agree, whereas only 4.8\% totally disagree); "I feel more secure to express desires and fantasies that I wouldn't otherwise express" (56.1\% agree and $11.5 \%$ disagree).

Factor 2, Preference for Cybersex, is the most interesting one for the researchers, because it attempts to identify individuals that are interested in cybersex to the exclusion of any other sexual activity.

The results of this study indicate that cybersex on chatlines allows people to subsequently pursue sexual activities, including offline dates with sexual purpose and sex by phone, which is more personalized than cybersex because of the voice, regarded by some as a source of sexual gratification. For example, $8.5 \%$ of the participants totally agree with the statement "I use these chatrooms exclusively to set up dates with sexual aims"; $12.5 \%$ totally agree with the statement "It's a good way to make a first selection of a partner for a real date." Concerning phone sex, $17 \%$ of respondents totally 
agree with the following two items: "I prefer sex over the phone to cybersex" and "Sex by phone arouses me."

As for the impact of cybersex on real relationships, we found a minority of individuals for whom cybersex has positive consequences for their lives, especially their relationships. For $14 \%$ of the individuals, online sex can intensify and improve real relationships with partners, and $12.5 \%$ totally agree with the item "Cybersex can 'spice up' my real relationship."

Over the course of our investigation, we came across an enormous variety of behaviors, not uncommon when one studies human sexual behavior; however, our analysis suggests the existence of two types of individuals.

1. Individuals who take advantage of the immediate nature of the online situation to obtain sex quickly: Their activity on chatlines is used as a filter in their search for people with the same sexual interests for later offline dates. They use chatrooms and online sexual activity as a starting point for a future sexual date in a real relationships. Because they want to achieve their sexual aims quickly, they go through a sequence of behaviors that start with a first contact on the chatline, continue with a telephone conversation, and end with a real date. The fear of rejection in real life, diminished by anonymity in the virtual world, could explain their use of online contact. For these people, cybersex is not of major interest; it is, rather, an excuse. Our findings indicate that the vast majority of individuals in chatrooms belong to this group.

2. Individuals who want and prefer cybersex and have no interest in a later real-life date: For these individuals, anonymity seems to be the great attraction, because it allows people to "take off their masks" or never actually use them, letting them truly express their interests, desires, and fantasies which, for various reasons, cannot be satisfied in the real world. These are individuals for whom online sexual activity is the primary and only objective, and they represent a minority in the chatrooms.

As Román Gubern (2002) wrote, "The Net is an Eden for those whom Dr. Lars Ullerstam called 'erotic minorities,' with their specialized tastes and their right to satisfy them. Repository of endless erotic fantasies, promiscuous cyberspace proves that sex is not between our legs but inside our heads." (Gubern, 2000, p. 122).

Because this study was based entirely on voluntary responses from selfselected users of chats, we have to consider possible sample bias. Until now we have not been able to get a random sample to study this populationchatroom users. We should also bear in mind that is it impossible to perform test-retest reliability (stability of answers over time) because of the inaccessibility of the sample for a second time. The converging validity study is compromised because we have no knowledge of any other means of evaluation. We view this work as a preliminary study that is merely the starting point to 
analyze methodological limitations to the investigation of a phenomenon that has major social and clinical consequences.

\section{REFERENCES}

Baker, N. (1992). Vox: A novel. New York: Vintage Contemporaries.

Baker, N. (1998). The fermata. New York: Vintage Contemporaries.

Carvalheira, A. A., \& Gomes, F. A. (2002a). Sexo online em Portugal: Uma investigação sobre Comportamentos Sexuais em Chats Portugueses. Psiquiatria Clinica, 23, $43-50$.

Carvalheira, A. A., \& Gomes, F. A. (2002b). Sexo online em Portugal: Estrutura Factorial do "Questionário de Comportamentos Sexuais nos Chats." Psiquiatria Clinica, 24, 123-130.

Childs, M. (1994). Lust online. Playboy, April.

Cooper, A., Boies, S., Maheu, M., \& Greenfield, D. (2000). Sexuality and the Internet: The next sexual revolution. In L. Szuchman, \& F. Muscarella (Eds.), Psychological perspectives on buman sexuality. New York: John Wiley \& Sons, 519-545.

Cooper, A., Morahan-Martin, J., Mathy, R., \& Maheu, M. (2002). Toward an increased understanding of user demographics in online sexual activities. Journal of Sex $\varepsilon$ Marital Therapy, 28, 105-129.

Cooper, A., \& Sportolari, L. (1997). Romance in cyberspace: Understanding online attraction. Journal of Sex Education and Therapy, 22, 7-14.

Cooper, A., Putman, D. E., Planchon, L. A., \& Boies, S. C. (1999). Online sexual compulsivity: Getting tangled in the Net. Sexual Addiction \& Compulsivity, 6 , 79-104.

Cooper, A., Scherer, C., Boies, S., \& Gordon, B. (1999). Sexuality on the Internet: From sexual exploration to pathological expression. Professional Psychology: Research and Practice, 30, 154-164.

Greenfield, D. (1999). Psychological characteristics of compulsive Internet use: A preliminary analysis. Cyber Psychology \& Behavior, 2, 403-412.

Gubern, R. (2000). O Eros Electrónico. Viagem Pelos Sistemas de Representação e do Desejo. Lisbon: Editorial Notícias.

López, F. (1997). Afecto y Sexualidad. In J. G. Zapian (Ed.), Avances en Sexología. Bilboa: Universidad del País Vasco, 23-62.

McKenna, K. Y., Green, A. S., \& Smith, P. K. (2001). Demarginalizing the sexual self. The Journal of Sex Research, 38, 302-311.

Morahan-Martin, J., \& Schumacher, P. (2000). Incidence and correlates of pathological Internet use among college students. Computers in Human Behavior, 16, 13-29.

Schnarch, D. (1997). Sex, intimacy and the Internet. Journal of Sex Education and Therapy, 22, 15-20.

SPSS. (1999). 10.0 for Windows. Chicago: Data, Inc.

Wysocki, D. (1998). Let your fingers do the talking: Sex on an adult chat-line. Sexualities, 4, 425-452. 


\section{APPENDIX. QUESTIONNAIRE ON SEXUAL BEHAVIORS IN CHATROOMS}

1. Cybersex is a healthy way of exploring sexual curiosity.

2. It gives me the opportunity to discover "new tricks" that I can use in real relationships later on.

3. It's a way of exchanging erotic fantasies with someone and enriching my erotic experiences.

4. My online sexual activity is important in my life.

5. My online sexual activity is important for my personal fulfillment.

6. Fantasy is what rules an online relation.

7. It gives me the opportunity to explore some sexual fantasies I don't explore in a real relationship.

8. It is very exciting to share fantasies online.

9. In my online relationships I am different from what I am in real relationships.

10. I have the opportunity to be whatever I want online.

11. In online relationships I quite often use "masks" and take on different identities.

12. In my online relationships I quite often pretend that I am of the opposite sex.

13. I can pretend whatever I want online and I've already done it some times.

14. I feel more secure in expressing desires and fantasies that I wouldn't otherwise express.

15. I can be more open and straightforward than in a face-to-face relationship.

16. Online I can honestly say to the other person what I feel and think.

17. I am more daring in my sexual fantasies.

18. I am less ashamed of expressing some of my erotic and sexual desires.

19. It's a matter of playing a role that has nothing to do with my real personality.

20. Cybersex can "spice up" my real relationship.

21. It can intensify and improve my real relationship with my partner.

22. Cybersex can be a good complement to the real relationship.

23. My online sexual relationships are harmful to my real relationship.

24. It's only important for people who don't have a partner in real life.

25. Physical contact is not fundamental for intimacy in a relationship.

26. I feel more pleasure in an online relationship than in a real one.

27. Online sexual activity is more satisfactory than real relationships.

28. Online sexual activity can be as satisfactory as real relationships.

29. Cybersex allows me to do things that are not possible in a real relationship.

30. Those who have sex online are not satisfied with their real relationship. 
31. It can help find a partner to begin a real (offline) relation.

32. I never feel completely at ease in my social relations.

33. Cybersex is motivated by loneliness.

34. I am shy and this way I find partners more easily.

35. I have difficulties in establishing contacts with people of the opposite sex in real situations.

36. In real situations I feel a certain anxiety on social occasions.

37. In a real relationship I get nervous during the first dates.

38. If I am rejected online I don't suffer that much.

39. I feel less anxious when I begin a relationship online.

40. I use these chatrooms exclusively to set up dates with sexual aims.

41. It's an effective way of meeting people in a later, real-life situation.

42. It's a good way to make a first selection of a partner for a real date.

43. It's a good way to obtain someone's cell phone number for a later date.

44. It is easier to meet people with the same views and sexual preferences online.

45. It is easier to find people with the same sexual interests online.

46. I find the game of seduction in real situations boring.

47. Online relationships allow for a quicker conquests of the other person.

48. An online relationship allows me to get to sex quickly.

49. Cybersex is one of the most important activities in my life at the moment.

50. It's the only way of having a full (authentic) relationship with someone.

51. Cybersex occupies most of my day.

52. After discovering cybersex I no longer had time to do other things.

53. I usually ask for a cell phone number.

54. I like to hear the voice of somebody I met online.

55. I've already spoken on the phone about sex with people I met online.

56. Sex by phone arouses me.

57. Before setting up a date with someone in the real world, I like to speak with that person on the phone.

58. I prefer sex over the phone to cybersex. 
Copyright $\odot 2003$ EBSCO Publishing 